\title{
Psicologia e pobreza no Brasil: Histórico, produção de conhecimento e problematizações possíveis
}

\section{Psychology and poverty in Brazil: History, knowledge production and possible questions}

\section{Psicología y pobreza en Brasil: Historia, producción de conocimiento y problematizaciones posibles}

\author{
Kíssila Teixeira Mendes* \\ Universidade Federal de Juiz de Fora - UFJ F, Juiz de Fora, Minas Gerais, Brasil \\ Pedro Henrique Antunes da Costa** \\ Universidade Federal da Paraíba - UFPB, João Pessoa, Paraíba, Brasil
}

\begin{abstract}
RESUMO
O presente artigo objetivou realizar uma análise sobre como a temática da pobreza tem historicamente comparecido nos estudos e parâmetros de atuação profissional do psicólogo brasileiro. Foi realizada uma revisão bibliográfica acerca do objeto de estudo, o resgate de produções pertinentes sobre a relação da Psicologia brasileira com a pobreza ao longo de seu desenvolvimento, bem como de documentos e parametrizações do Conselho Federal de Psicologia. Observamos um crescimento do envolvimento da Psicologia com a pobreza e demais expressões da "questão social", atrelado com a maior vinculação da profissão com as políticas públicas e sociais. $O$ debate entre "questão social", pobreza e Psicologia, contextualizado em diferentes fases do capitalismo, face às particularidades brasileiras e atual conjuntura, evidencia as contradições: autocrítica acerca do distanciamento com a realidade brasileira e insuficiências teórico-práticas, mas com a hegemonia na Psicologia ainda se fazendo valer por meio de leituras e práticas individualizantes, psicologizantes, perpetradoras da ordem. Dessa forma, uma Psicologia compromissada com a compreensão e superação da pobreza, assim como do sistema que a forja e nela se sustenta, requer a identificação e libertação de sua própria pobreza.
\end{abstract}

Palavras-chave: Psicologia, história social, pobreza, questão social, Brasil.

\section{ABSTRACT}

The present article aims to analyze how the issue of poverty has historically appeared in studies and parameters of the professional work of Brazilian psychologists. A bibliographic review about the object of the study was elaborated, with the retrieval of relevant works about the relationship between Brazilian Psychology and poverty throughout its development, as well as documents and parametrizations of the Federal Council of Psychology. We see an increase in the involvement of Psychology with poverty and other expressions of the "social issue", linked to the greater bondage of the profession with public and social policies. The debate 
between "social issue", poverty and Psychology, contextualized in different phases of capitalism, in view of the Brazilian characteristics and current situation, shows the following contradictions: self-criticism about distancing from Brazilian reality and theoretical-practical insufficiencies, but with the hegemony in Psychology still being enforced through individualizing, psychologizing readings and practices, perpetrating the order. In this way, a Psychology committed to understanding and overcoming poverty, as well as the system that forges and sustains it, requires the identification and liberation of its own poverty.

Keywords: Psychology, social history, poverty, social question, Brazil.

\section{RESUMEN}

El presente artículo apuntó a realizar un análisis sobre cómo la temática de la pobreza ha formado parte históricamente en los estudios y parámetros de actuación profesional del psicólogo brasileño. Se realizó una revisión bibliográfica acerca del objeto de estudio y un rescate de producciones pertinentes sobre la relación de la Psicología brasileña con la pobreza a lo largo de su desarrollo, así como de documentos del Consejo Federal de Psicología. Observamos un crecimiento de la implicación de la Psicología con la pobreza y demás expresiones de la cuestión social, vinculada con la mayor ligazón de la profesión con las políticas públicas y sociales. El debate entre "cuestión social", pobreza y Psicología, contextualizado en diferentes fases del capitalismo, frente a las particularidades brasileñas y la coyuntura actual, evidencia las siguientes contradicciones: autocrítica acerca del distanciamiento con la realidad brasileña y las insuficiencias teóricoprácticas, empero existe una hegemonía en la Psicología que todavía se hace valer por medio de lecturas y prácticas individualizantes, psicologizantes, perpetradoras del orden. Así, una Psicología comprometida con la comprensión y superación de la pobreza y con el sistema que la forja y en ella se sustenta, requiere de la identificación y liberación de su propia pobreza.

Palabras clave: Psicología, historia social, pobreza, cuestión social, Brasil.

\section{I ntrodução}

O presente artigo objetiva realizar uma análise sobre como a temática da pobreza tem historicamente comparecido nos estudos e parâmetros de atuação profissional da Psicologia brasileira. Para tal, foi realizada uma revisão bibliográfica acerca do objeto de estudo, o resgate de produções pertinentes sobre a relação da Psicologia com a pobreza ao longo de seu desenvolvimento no país, e documentos do Conselho Federal de Psicologia (CFP). A partir da historicização da ciência e profissão, bem como de conceitos como "questão social" e pobreza, suas abordagens e contextualizações em diferentes fases do capitalismo, com ênfase nas particularidades brasileiras e atual conjuntura, visou-se compreender como nossa Psicologia se apropria da pobreza e trabalha com ela.

Compreendemos a pobreza como manifestação da "questão social", que, por sua vez, é constitutiva da sociedade capitalista, oriunda da contradição capital-trabalho e da lógica de acumulação capitalista 
(Montaño, 2012). Na tradição marxista, este é um conceito, não uma categoria, pois não existe na realidade (daí, as aspas); o que se encontra são suas expressões, como a pobreza, o desemprego estrutural etc. Apesar do referencial, a questão social é abordada por uma pluralidade de frentes teóricas. Começa a ser usada a partir da separação positivista entre social e econômico, que naturaliza ambos, tornando-os a-históricos. Esse movimento de separação tem origem nas revoluções liberais de 1830-48 que evidenciaram a perda do caráter crítico revolucionário da burguesia, sobretudo, por ignorarem - papel da luta de classes e o estudo das relações sociais pela Economia. Como consequência, a questão social passa a ser encarada "não como resultado da exploração econômica, mas como fenômenos autônomos e de responsabilidade individual ou coletivados setores por elas atingidos" (Montaño, 2012, p. 272).

No Brasil - e América Latina - a questão social, tendo na pobreza a sua máxima expressão, também é oriunda da perpetuação de um antagonismo de classes, que se imbrica nas dimensões étnico/raciais, de gênero e de concentração de renda, cujas raízes estão na colonização, no regime escravocrata e nos sistemas de monoculturas latifundiárias (Cidade, Moura Jr. \& Ximenes, 2012). Dessa forma, produz-se aqui um cenário histórico de profundas desigualdades e uma situação de dependência e subordinação ao centro do capitalismo que se retroalimentam.

Porém, a expansão capitalista no século $X X$, o modelo fordista e a ampliação das lutas trabalhistas fizeram surgir novas formas de incorporação das demandas e necessidades da classe trabalhadora, sendo o Estado um ator principal para institucionalização de conflitos. Trata-se do capitalismo monopolista, que se configura tardiamente no Brasil, e do Estado de Bem-Estar Social, que, a despeito das tentativas com a constituinte e Constituição de 1988, nem chegou a ser implantado no país, sendo solapado pelo projeto neoliberal dos governos seguintes à sua promulgação. Nessa configuração, a questão social se transfere para a política, sendo enfrentada segmentadamente por políticas setoriais que compreendem a pobreza como consequência do subdesenvolvimento, um mero problema de distribuição (Montaño, 2012).

Circunscritas a este movimento, estão as ciências e práticas psi, fazendo com que indaguemos seu papel nele, visto que a concretude da pobreza gera impactos subjetivos e passa ser conformada por eles, dialeticamente. Historicamente, a Psicologia, em todo o mundo, ocupou o local da neutralidade e objetividade. Em meados dos anos 1960, numa América Latina de guerras civis, regimes ditatoriais, imperialismo, intensificação da desigualdade social etc., esta disciplina passou a ser convocada a pensar seu papel nesta realidade. No Brasil dos anos 1990 e 2000, com a reabertura democrática, ampliação das políticas públicas e inserção do psicólogo nesses 
campos, o desafio foi intensificado (Yamamoto \& Oliveira, 2010; Macedo et al., 2011; Lacerda Júnior, 2013).

O intuito, assim, é o de contribuir para o entendimento e trabalho do psicólogo em interface com a pobreza conformante da realidade brasileira e sua materialização nos sujeitos e cotidiano, face ao momento atual em que ela se exacerba, juntamente à intensificação da crise estrutural do capitalismo e a ofensiva neoliberal. Ademais, visamos refletir sobre as implicações psicossociais da pobreza e em como pensar em reflexões e atuações profissionais, sobretudo no âmbito das políticas públicas, mais condizentes com as necessidades e realidades concretas da população, bem como apontar horizontes transformadores. A partir do exposto, o artigo é dividido da seguinte forma: apresentação de um panorama histórico da profissão e produção de conhecimento sobre a pobreza na Psicologia Brasileira; a posição e produções do CFP nesse contexto; e considerações sobre questão social, pobreza e Psicologia, face à atual conjuntura, finalizando com um debate sobre as implicações psicossociais da pobreza e horizontes possíveis.

\section{Psicologia e pobreza: panorama da profissão e produção de conhecimento}

É impossível estabelecer um recorte, delimitando o início da abordagem da pobreza pela Psicologia. Até mesmo, porque, como vimos, a pobreza é constitutiva de nossa sociabilidade, e o campo psi, sobretudo na América Latina, querendo ou não, é atravessado por ela. A própria tentativa de delimitação do surgimento da Psicologia no país, se mostra estéril, pois como aponta Massimi (2004), ideias psicológicas circulavam na cultura brasileira já no século XVI, muito antes da criação das instituições superiores de ensino (no século XIX) e, mesmo, da regulamentação da profissão (1962). No que tange às origens das ideias psicológicas no Brasil, elas se voltaram para as questões sociais, englobando a pobreza e o pobre "de uma posição dirigista, iluminada, fácil de entender-se, a vista de indigência cultural da população no período, e da preocupação conquistadora ou catequética da inteligência brasileira de então" (Pessotti, 1988, p. 20).

A partir dessas origens, agregando perspectivas científicas positivas, e se associando com a Medicina, Pedagogia, dentre outras, a Psicologia brasileira vai se institucionalizando nos séculos XIX e XX, com maior impulsão no período "nacional-desenvolvimentista" (19301964). Tem como principais campos de atuação a clínica, a educação e o "mundo do trabalho" (Pereira, 2010; Pessotti, 1988) e atuações predominantes de psicoterapia privativa, diagnósticos, psicometria, orientação e seleção profissional e solução de problemas de 
ajustamento (Brasil. Presidência da República, 1962; Azzi, 2010; Pereira, 2010). Nesse cenário, são bastante ilustrativos e pertinentes os avisos de Azzi (2010):

“a psicologia deve evitar de se tornar instrumento de opressão social, confundindo (e esta confusão seria por demais simples, ou melhor, por demais desonesta) uma ordem social injusta com uma desordem psicológica e consequentemente tentar substituir ações sociais adequadas por medidas mais ou menos paternalísticas e inócuas de higiene mental, relações humanas ou coisa que se equivalha" (p. 117).

Apesar do pedido, a Psicologia manteve-se hegemonicamente distanciada das maiorias populares (em especial as mais pauperizadas), reproduzindo teorias, conceitos e técnicas importados e compromissadas com a manutenção da ordem e projeto de desenvolvimento do país (Lacerda Júnior, 2013). Para "uma escassa minoria, dotada de recursos" a Psicologia se torna uma "atividade de luxo" (Pereira, 2010, p. 161); para a população pauperizada - o grosso da classe trabalhadora - ela se volta para o ajustamento e adaptação em prol da modernização e desenvolvimento. A abordagem e tratamento das ditas "questões" sociais as toma como produtos das mentes, objetivando explicar problemas da sociedade olhando para o que se passa dentro da cabeça das pessoas e intervindo nelas (Lacerda J r., 2010). No caso da pobreza, esta aparece como "sujeito psicológico" (Oliveira \& Amorim), reforçando uma lógica de individualização, psicologização e culpabilização dos pobres. Sobre isso, Botomé (2010, p. 176) indaga: "Os psicólogos e administradores da Psicologia, como ciência e como profissão, mudarão essas tendências? O que dará a Psicologia a um povo de um país pobre como o Brasil?".

Buscando mudar essa lógica, é inegável a influência de lutas históricas da Psicologia, ganhando fôlego a partir dos anos 1960 - o que, também, ocorreu em outras áreas -, almejando um saber-fazer comprometido com a realidade brasileira e latino-americana e sua transformação social. Nesse cenário, a Psicologia Social crítica, a Psicologia Social Comunitária, o Projeto de Compromisso Social da Psicologia, o CFP, entre outros movimentos, organizações e áreas, confluíram a uma maior aproximação das camadas populares, a partir de tentativas de reformulações teórico-práticas e ético-políticas (Lacerda Júnior, 2013). De acordo com Pessotti, em 1988, somente após 25 anos de regulamentação da profissão e "mais de um século e meio" de ciência Psicológica no país, excluindo seu período préinstitucional, é que "a nossa psicologia se volta decididamente para as condições socioeconômicas da população" (Pessotti, 1988, p. 31). 
A despeito destes movimentos, Yamamoto (2009) conclui que a aproximação da Psicologia com as classes populares e mais pauperizadas não se deu apenas devido a uma súbita consciência de seu papel, mas, principalmente, por motivações corporativistas, em decorrência de contingências do mercado de trabalho (aumento no número de psicólogos e diminuição da demanda clínica pela classe média afetada pela crise econômica dos anos 1970/1980). Outros dois importantes vetores para esse movimento foram: a ampliação do campo de trabalho psi, a partir da redefinição do setor de bem-estar social e reabertura democrática; e os embates ideo-teóricos, potencializados por uma maior inserção de psicólogos nos movimentos sociais, entidades de categoria, sindicatos etc., possibilitando redefinições teóricas (Yamamoto, 2009).

O estudo de Dantas e Yamamoto (2010) faz um mapeamento histórico das produções psi sobre o tema, sendo bastante esclarecedor em termos de como a Psicologia brasileira se ocupou em estudar e abordar (teórica e concretamente) a pobreza. Dentre os vários achados da pesquisa, gostaríamos de destacar as seguintes tendências: (a) o crescimento das produções a partir da década de 1980; (b) vinculação da pobreza a temas mais amplos ou centrais; (c) importância dos estudos com crianças e adolescentes; (d) predominância do assistencialismo, da pobreza como variável ou critério para recorte da população estudada, e da descrição e caracterização da população pobre; e (e) discussões circunscritas à Psicologia Social, com destaque também à Psicologia Escolar/Educacional (devido aos estudos com crianças e adolescentes).

Cabe ressaltar que estes dados se relacionam com o desenvolvimento da sociedade brasileira, bem como da própria Psicologia no país. São relevantes para esse quadro: o aumento no número de periódicos, maior incentivo à pesquisa e criação de Programas de Pós-Graduação na área; crise econômica e aguçamento da desigualdade social, atrelada às restrições de liberdades democráticas gerando um conjunto de lutas e mobilizações contra o regime autocráticoburguês; conquistas, como a reabertura democrática, promulgação da Constituição de 1988, do Sistema Único de Saúde (SUS) (1988 e 1990), Estatuto da Criança e Adolescente (1990), Lei Orgânica da Assistência Social (1993) etc.; e os tensionamentos internos à Psicologia e sua hegemonia individualista, privatista e assistencialista, juntamente com a inserção nas políticas sociais (Yamamoto, 2009; Dantas \& Yamamoto, 2010; Yamamoto \& Oliveira, 2010).

Mais recentemente, Ximenes, Moura Júnior e Lima (2015) analisaram a presença da temática da pobreza nos trabalhos da 5a Conferência Internacional de Psicologia Comunitária, de 2014, em Fortaleza. Com relação aos resultados, destacamos: (a) menos de $10 \%$ dos trabalhos abordavam a pobreza; (b) predominância de trabalhos relacionados 
com as políticas públicas e, em seguida, que se ancoravam no debate e experiência sobre a formação em Psicologia; (c) a maioria dos trabalhos não definia o que era pobreza, carecendo de aprofundamentos teóricos, e/ou abordavam o fenômeno de maneira adjacente; (d) nos trabalhos que explicitaram o enfoque teóricometodológico, observou-se uma mescla entre a perspectiva monetarista, onde a pobreza baseia-se na limitação de renda, multidimensional, considerando também a privação de oportunidades e liberdade; e (e) perspectiva restrita de caracterização da pobreza a um determinado contexto de atuação. Apesar de nem todos os trabalhos serem do Brasil, cerca de $60 \%$ era em língua portuguesa, 0 que nos faz pensar que, pelo menos metade, era sobre o Brasil.

Silva (2018) analisa sobre a pobreza, formação e atuação de psicólogos nas políticas públicas, constatando um cenário contraditório, com manutenção dos preconceitos e distorções acerca da pobreza e do pobre, mas também com compreensões mais abrangentes sobre a pobreza e outras manifestações da questão social, rompendo com naturalizações e individualizações. Ao mesmo tempo em que as políticas públicas e a pobreza passam a ter maior espaço nas grades de alguns cursos de pós-graduação, em outros são insuficientes.

De modo a complementar os achados dessas pesquisas, realizamos uma busca na SciELO por "psicologia" e "pobreza". O panorama encontrado corrobora as análises de Dantas e Yamamoto (2010). Poucos trabalhos tomaram a pobreza como tema central, enquanto fenômeno social multideterminado, compreendendo suas vinculações objetivas e subjetivas (Euzébios Filho \& Guzzo, 2009; Melsert \& Bock, 2015; Moura Júnior \& Ximenes, 2016).

Portanto, esse histórico indica que existe uma maior preocupação da Psicologia em entender a realidade das maiorias populares, e nelas, as mais pauperizadas, com maior aproximação e responsabilização acerca da transformação de suas condições de vida. Isso reverbera em mudanças nos arcabouços teórico-metodológicos do psicólogo, ao mesmo tempo em que o processo inverso também é verdadeiro, com ambos se consubstanciando dialeticamente. Não se trata apenas de um movimento interno da Psicologia brasileira, mas também resultante e expressão das transformações na sociedade capitalista e, particularmente, brasileira (Dantas \& Yamamoto, 2010). Contudo, as vicissitudes de nosso país, as limitações da própria Psicologia no geral e no Brasil, contribuem, ao mesmo tempo, para leituras e ações que almejam maior contextualidade e transformação social, e para as perspectivas hegemônicas individualizantes e psicologizantes, concebendo a pobreza como "sujeito psicológico" (Oliveira \& Amorim, 2012), alvo de caridade e assistencialismo, em suma, perpetuadoras da ordem. 


\section{Psicologia e pobreza: a posição do CFP}

Almejando aprofundar o processo histórico de compreensão e abordagem da pobreza pela Psicologia brasileira, é importante considerar a posição de seu conselho, como expressão e, também, impulsionador dos próprios rumos da profissão (CFP, 1988; Yamamoto \& Oliveira, 2010). Para isso, realizamos uma busca na página eletrônica do CFP (site.cfp.org.br), na parte referente às suas publicações, tentando compreender como a entidade representativa da categoria tem se posicionado e buscado orientar a formação e prática profissional sobre o tema.

Inicialmente, poderíamos concluir que não há uma preocupação do Conselho sobre a pobreza, pois não existe nenhuma publicação específica sobre tema. Contudo, analisando o teor dos materiais disponibilizados pelo CPF em sua página, constatamos um movimento da entidade em promover debates e qualificações acerca da formação e trabalho do psicólogo no que tange ao entendimento da pobreza e demais "questões" sociais como constitutivas de nossa organização social e, portanto, dos sujeitos que nela se forjam e a conformam.

Pudemos observar que a pobreza aparece de maneira transversal e compreendida por um pluralismo teórico-metodológico, em referências técnicas para o trabalho do psicólogo em determinados campos (com ênfase nas políticas públicas de saúde, assistência social, educação e segurança pública), mas também em relatórios, cartilhas e livros sobre temáticas, como: saúde, saúde mental, álcool e outras drogas, processos educacionais, juventude e socioeducação, políticas de encarceramento, territorialidade e luta pela terra, tendo na noção de direitos humanos e o compromisso ético-político para a sua garantia como os principais aportes e horizontes. Ademais, é demonstrada uma preocupação com a complexidade de organização de nosso modelo de sociabilidade, erigida sobre e por imbricamentos de classe, cor/raça/etnia, gênero e sexualidades, idade, território, dentre outros, e para a consequente necessidade da Psicologia brasileira transformar a si mesma, ao tomar como objetivo a transformação dessa nossa realidade estruturalmente classista e desigual, racista, patriarcal, machista, misógina, heteronormativa etc. Algumas aproximações e descompassos são observados na análise dos materiais do CFP e da produção em Psicologia, sintetizada anteriormente. As aproximações são: constatação de que a pobreza não é estudada pela Psicologia como categoria central, associada a temas, como a juventude, saúde, assistência social etc.; a dissociação da pobreza de outros problemas, vistos como "questões" sociais e não como expressões da questão social; dificuldades do trabalho do psicólogo com a população pobre e insuficiências teóricoconceituais, práticas e formativas; e a centralidade da Psicologia Social e Escolar/Educacional. Em termos dos distanciamentos, 
observamos que, na produção acadêmica, a heterogeneidade se estendeu também à compreensão da pobreza, indo desde uma compreensão mais abrangente, que almeja uma transformação social, passando pelas relações que ela possui com outras "questões" sociais, mas também concebendo-a como uma "variável" analítica e/ou focalizando a descrição da população pobre, de modo a estudar dimensões psicológicas ou sociais associadas, desconsiderando-a, como estrutural e imanente à sociedade capitalista (corroborando Dantas \& Yamamoto, 2010). Já nos materiais do CFP, observamos, dentro da pluralidade teórico-metodológica, maior unidade em termos de uma visão crítica, associando a pobreza e demais "questões" à sociedade em que vivemos, almejando transformá-la e, por conseguinte, a própria Psicologia.

A Tabela 1 apresenta os materiais encontrados, com seus respectivos anos. Podemos observar um crescimento no número de publicações nos últimos 10 anos. Em consonância com Macedo et al. (2011), os anos 2000 marcam a profissão pela ampliação de sua inserção nas políticas públicas, com articulações e movimentos da categoria, lideradas pelo Sistema Conselhos (Federal e Regionais) sobre as principais questões que envolvem a realidade brasileira, sendo a pobreza uma delas. Com a aprovação da Política Nacional de Assistência Social e implantação do Sistema Único da Assistência Social (SUAS), em 2004, o psicólogo passou a trabalhar em sua estrutura organizativa. Nestes "novos" contextos, "novos" problemas surgem, complexificados pelos velhos. Ao se deparar, mais do que nunca, com a pobreza e demais "mazelas" sociais, são escancaradas as dissonâncias entre a realidade brasileira e a Psicologia (formação e prática), com necessidade não apenas de reformulações e adequações no âmbito do conhecimento teórico-técnico e do trabalho, mas de criação de novos aportes e mudanças em sua identidade e quefazer (Yamamoto \& Oliveira, 2010; Macedo et al., 2011). 
Tabela 1: Publicações do site do CFP que abordam a relação entre Psicologia e pobreza

\begin{tabular}{|c|c|}
\hline Publicaçöes & Ano \\
\hline "Adolescência e psicologia: concepçס̃es, práticas e reflexões críticas" & 2002 \\
\hline "Relatório sobre as inspeções a unidades de internação de adolescentes em conflito com a lei" & 2006 \\
\hline "Diretrizes para atuação e formação dos psicóloqos do sistema prisional brasileiro" & 2007 \\
\hline "IV Seminário Nacional Psicologia e Políticas Públicas" & 2007 \\
\hline "Ano da Psicoloqia na Educação - Textos Geradores" & 2008 \\
\hline "Falando sério sobre prisōes, prevenção e segurança pública" & 2008 \\
\hline "Atuação do psicóloqo no sistema prisional" & 2010 \\
\hline "Psicologia e mobilidade: o espaço público como direito de todos" & 2010 \\
\hline "Subjetividade do consumo de álcool e outras droqas e as políticas públicas brasileiras" & 2010 \\
\hline $\begin{array}{l}\text { "Contribuições do Conselho Federal de Psicologia para a constituição da Rede de Atenção Psicossocial } \\
\text { no "Sistema Único de Saúde a partir do Decreto } 7.508 / 2011^{\prime}\end{array}$ & 2011 \\
\hline "Psicologia e diversidade sexual: desafios para uma sociedade de direitos" & 2011 \\
\hline $\begin{array}{l}\text { "Relatório da } 4^{\circ} \text { Inspeção Nacional de Direitos Humanos: locais de internação para usuários de } \\
\text { droqas" }\end{array}$ & 2011 \\
\hline "Senhoras e senhores gestores da Saúde, Como a Psicologia pode contribuir para o avanço do sus" & 2011 \\
\hline "V Seminário Nacional Psicologia e Políticas Públicas - Subjetividade, Cidadania e Políticas Públicas" & 2011 \\
\hline "Droqas e Cidadania" & 2012 \\
\hline "Prêmio Profissional: "Democracia e Cidadania Plena das Mulheres" & 2012 \\
\hline "Referências técnicas para a atuação das(os) psicóloqas(os) no Sistema Prisional" & 2012 \\
\hline "Drogas, Direitos Humanos e Laço Social" & 2013 \\
\hline "Redução da idade penal: socioeducação não se faz com prisão" & 2013 \\
\hline $\begin{array}{l}\text { "Referências Técnicas para a Atuação de Psicólogas/os em Politicas Públicas de Álcool e Outras } \\
\text { Droqas" }\end{array}$ & 2013 \\
\hline "Referências Técnicas para Atuação das(os) Psicólogas(os) em Questరes Relativas a Terra" & 2013 \\
\hline $\begin{array}{l}\text { "Referências técnicas para atuação de psicólogas (os) em Programas de Atenção à Mulher em situação } \\
\text { de Violência" }\end{array}$ & 2013 \\
\hline "Referências técnicas para Atuação de Psicólogas(os) na Educação Básica" & 2013 \\
\hline "Referências Técnicas para Atuação de Psicólogas(os) no CAPS - Centro de Atenção Psicossocial" & 2013 \\
\hline $\begin{array}{l}\text { "Referências técnicas para Prática de Psicólogas(os) no Centro de Referência Especializado da } \\
\text { Assistência Social - CREAS" }\end{array}$ & 2013 \\
\hline "Inspeção a manicômios - Relatório Brasil" & 2015 \\
\hline $\begin{array}{l}\text { "Mitos e Verdades Sobre a Justiça Infanto Juvenil Brasileira: Por que Somos Contrários à Redução da } \\
\text { Maioridade Penal?" }\end{array}$ & 2015 \\
\hline "Aborto e (Não) Desejo de Maternidade(s): questões para a Psicologia" & 2016 \\
\hline "Estatuto da Criança e do Adolescente: refletindo sobre sujeitos, direitos e responsabilidades" & 2016 \\
\hline "Louco Infrator e o Estigma da Periculosidade" & 2016 \\
\hline "O Trabalho da (o) psicóloga (o) no sistema prisional: Problematizaçס̃es, ética e orientaçס̃es" & 2016 \\
\hline "Psicoloqia Escolar: que fazer é esse?" & 2016 \\
\hline "Relações Raciais: Referências Técnicas para atuação de psicólogas/os" & 2017 \\
\hline "Relatório da Inspeção Nacional em Comunidades Terapêuticas - 2017 " & 2018 \\
\hline
\end{tabular}


Entendemos que o maior envolvimento (teórico-conceitual, prático e ético-político) da Psicologia com a pobreza e demais expressões da questão social se atrela à maior vinculação da profissão com as políticas públicas e sociais. Nesse processo, a criação do Centro de Referência Técnica em Psicologia e Políticas Públicas (CREPOP) em 2006 é um indicativo desse comprometimento, com sinalizações da entidade para sua categoria. Tal fator também vem a influenciar os materiais aqui analisados, com somente uma publicação anterior a 2006. Outra limitação da análise se refere ao fato de desconsiderarmos as publicações dos Conselhos Regionais de Psicologia e outros documentos do CFP, como regulamentos, projetos de lei etc.

\section{Algumas problematizações: questão social, pobreza e psicologia}

Entendemos que a práxis do psicólogo brasileiro com a pobreza está além do que é publicado. Levando em consideração essa limitação, os achados apresentados sinalizam para o crescimento da interface entre Psicologia e pobreza, com destaque para as políticas públicas. Articulando-os com nossa atual conjuntura, gostaríamos de tecer algumas reflexões. Sendo a pobreza uma expressão da questão social, que, por sua vez, é imanente à sociabilidade capitalista, ela não será superada dentro dessa própria sociabilidade, por mais que se formulem e implementem políticas que, na melhor das hipóteses, conseguirão dirimi-la e gerenciá-la, mas não superá-la. Não intentamos com essa ressalva diminuir a importância das políticas públicas, sobretudo as de corte social, ainda mais quando consideramos nosso profundo antagonismo social que se consubstancia em nossa condição dependente, racista e patriarcal. Entretanto, devemos nos questionar: (1) A abordagem da pobreza pela Psicologia contribuiu para a compreensão da realidade brasileira e um trabalho transformador do psicólogo? (2) Quais os limites e possibilidades do psicólogo como trabalhador e, portanto, atravessado pelas contradições imanentes ao capitalismo, na abordagem da pobreza? (3) Quais as contradições que a abordagem psi acerca da pobreza e demais manifestações da questão social carrega ao estar vinculada essencialmente às políticas públicas e sociais? (4) Quais caminhos podemos trilhar?

Analisando a situação brasileira no contexto de reestruturação produtiva e implantação da doutrina neoliberal, como respostas à crise estrutural do capitalismo monopolista que surgiu nos anos 1970, mas que adentrou mais fortemente no Brasil nos anos 1990, Fontes (2010) adverte sobre os perigos da centralidade da abordagem à 
pobreza, desconsiderando a análise "da relação entre as classes e destas com as formas específicas da acumulação de capital" (p. 347); isto é, os problemas de se limitar aos efeitos (pobreza), ao invés de se centrar nas causas (contradição capital-trabalho e acumulação do capital, por exemplo). A isto, ela chama de "pobretologia". Tal perspectiva, alinhada com o Banco Mundial (BM), Fundo Monetário Internacional (FMI) e demais representantes do capital internacional, encontra-se associada a um politicismo que imputa a responsabilidade pelas desigualdades brasileiras à má gestão estatal ou ao seu caráter supostamente patrimonialista (quando não aos próprios sujeitos), fechando os olhos para a natureza classista deste próprio Estado, como forma de gerência do capital.

É válido ainda questionarmos como essas agências internacionais tratam a pobreza. Desde a década de 1980, o FMI pauta condições a seus países "clientes". Para emprestar dinheiro, orienta como determinadas políticas devem ser estruturadas e essa orientação impõe padrões internacionais às realidades locais. Assim, os Estados endividados passam por reformas estimuladas por agências como o $\mathrm{BM}$ e o FMI, se pautando pela lógica do capital imperialista, perdendo ainda mais autonomia para sua autogerência. Além disso, o BM passou também a ditar reformas na saúde e educação: "Estado mínimo", questionamento da equidade, universalidade etc. A ideia era que, se os serviços sociais de má qualidade não atendiam a quem mais precisava - os pobres -, logo, deveriam ser destinados somente a essa população. A classe média, por sua vez, adere aos serviços privados e o sucateamento dos serviços públicos, tidos como benesses, é visto como natural: “assim, o Estado neoliberal constrói uma faceta assistencialista como contrapartida de um mercado livre, e o BM pode se vangloriar de suas políticas com face humana, que ensinam a lutar contra a pobreza" (Accorssi, Scarparo \& Guareschi, 2012, p. 542).

O Estado é tido como ineficiente ou corrupto e o mercado e a iniciativa privada são vendidos como a excelência em gestão, surgindo como loci desejáveis de gerência da pobreza e políticas sociais. Segundo Fontes (2010), a "pobretologia" tem como fundamento e intenção "eliminar as análises totalizantes sobre as condições internacionais de produção da desigualdade e estimulando financeiramente estudos limitados a mensurá-la, capturando-a como alvo prioritário de atuação 'coletiva' mercantil-filantrópica e de expansão do capital-imperialismo" (p. 192). Temos um apagamento dos antagonismos e lutas de classes e, portanto, das razões de produção da própria pobreza e dos meios que serviriam para suprimila, superando o capitalismo.

Com o aumento da desigualdade e desmonte das políticas, a partir da desregulamentação do Estado e reestruturação do capital, surge o Terceiro Setor, caracterizado pelas organizações não governamentais 
para ocupar o papel (até então, do Estado) de provedor e gerenciador das políticas públicas. É importante ainda pensar em como o psicólogo se inseriu nesses novos postos de trabalho. Embora os financiamentos possam vir do Estado, de forma direta ou indireta, a ideia de livre competição ocupou também espaço na "comercialização do sofrimento humano" (Accorssi, Scarparo \& Guareschi, 2012, p. 543). A pobreza torna-se objeto de lucro e, logo, sua manutenção também. Passa a ser vista de maneira parcializada, distante, não universal e constituinte (e necessária) à manutenção da ordem, "docilizando" essa camada da população.

Assim, a pobreza no atual contexto neoliberal e de crise do capital, adquire novas roupagens: desvinculação da questão social e luta de classes, desregulamentação da intervenção estatal, focalização e perda de direitos dos trabalhadores (por exemplo, as contrarreformas previdenciária e trabalhista). Entretanto, não deixa de se vincular com mecanismos nevrálgicos do capitalismo, não se tratando, então, de uma "nova" pobreza, tampouco uma "nova" questão social (Lima, 2014). É reforçado o enfoque individual na pobreza e voltam à cena a figura da caridade, além do debate do terceiro setor, da filantropia empresarial e voluntariado. Os serviços sociais passam a ser cada vez mais lucrativos. Embora o problema continue sendo visto como de distribuição, há uma diferença, pois a pobreza passa a ser agora encarada como problema de déficit de oferta de bens e serviços: "em lugar de estimular o consumo (com ações redistributivas), o Estado deve estimular o capital a investir, garantindo e preservando o lucro frente às flutuações do mercado, particularmente em contexto de crise" (Montaño, 2012, p. 277).

Entretanto, não só os períodos de crise evidenciam o conflito do trabalhador: o próprio desenvolvimento do capitalismo tende a marginalizar ciclicamente um grande contingente de trabalhadores, por meio da substituição do trabalho por recursos tecnológicos, agravando problemas, cujo "custo" social, por sua vez, passam a ser responsabilidade do indivíduo e/ou de sua família. O conceito de "excluído" entra nesse debate, porém, sem adquirir sentido de classe social como outrora constituíram "operários", por exemplo. Trata-se de um discurso incorporado ao sistema para definir aqueles diferentes de si e "é apenas um rótulo abstrato, que não corresponde a nenhum sujeito de destino: não há possibilidade histórica nem destino histórico nas pessoas e nos grupos sociais submetidos a essa rotulação" (Martins, 2003, p. 30). Isso porque não parte da concepção de transformação social e sim da de que a integração na sociedade de consumo é o ideal. Assim, as mudanças sociais que diluíram a identidade de trabalhador pela de "pobre" ou "excluído" devem também ser pensadas em razão de suas consequências, como a desmobilização de classe e lógica de coisificação. 
Portanto, "exclusão" se torna um conceito controverso e pouco preciso e, por isso, a preocupação em aprimorá-lo ou não o utilizar. Isso porque, grande parte das análises trata exclusão como sinônimo de pobreza, não enfatizando a desigualdade social estrutural (ou seja, a questão social). Além disso, segundo Netto (2011), essas categorias reduzem a questão social do capitalismo à mera condição de acesso, sobretudo, a bens de consumo.

No que tange às implicações psicossociais da pobreza, a definição do "pobre" obviamente impacta quem é definido enquanto tal, sendo ela constitutiva de sua identidade. Por mais que falar sobre identidade implique em resgatar o simbólico, mais ainda, pressupõe que nos assentemos na realidade concreta. E a concretude da pobreza gera impactos subjetivos, que, dialeticamente, a reificam, como: sentimentos de vergonha, e humilhação, baixas expectativas em relação ao futuro, naturalização e estigmatização da pobreza, levando à (auto) depreciação, aceitação de sua condição e incorporação da ideologia meritocrática (Euzébios Filho \& Guzzo, 2009; Melsert \& Bock, 2015; Accorsi \& Scarparo, 2016; Moura Júnior \& Ximenes, 2016).

Dessa forma, a redução da pobreza em um enfoque exclusivamente monetário (da renda), e sua dissociação de um caráter de classe, indicam a diminuição do indivíduo ao status de consumidor (ou mercadoria): noção incorporada pelos sujeitos (Euzébios Filho \& Guzzo, 2009). Isso não significa desconsiderara dimensão econômica como preponderante nas relações, com a subjetividade humana materializando a lógica de exploração, vinculada a mecanismos de opressão, seja entre pobres e ricos ou entre os próprios explorados e oprimidos. Esse ajustamento à ideologia dominante é correspondente à Ideologia de Submissão e Resignação (Cidade, Moura Jr. \& Ximenes, 2012), onde tal realidade é vista como única.

A desigualdade passa a ser tida como natural, contribuindo para o fatalismo (Moura Júnior \& Ximenes, 2016; Martin-Baró, 2017), reificando a exploração. Essas perspectivas, porém, não são de origem individual, mas advém da não mudança estrutural societária (Guzzo \& Lacerda Júnior, 2007), o que nos leva a tomar como horizonte máximo a supressão por completo de nossa sociabilidade, ou seja, almejar a emancipação humana. Nesse sentido, Lima (2014) faz uma advertência não só para os perigos de a Psicologia reduzir a emancipação humana (que evoca a supressão do capitalismo e a real libertação dos seres humanos) à emancipação política (restrita aos marcos do capitalismo), mas para a simplificação dessa já limitada emancipação política a uma "emancipação subjetiva", de essência idealista psicologizante, como se a consciência fosse produto da mente isolada.

Os profissionais que atuam em contextos de pobreza no capitalismo (ainda mais nos moldes neoliberais) necessitam compreender que tal 
sociedade está construída sobre princípios "não humanos" como o individualismo, a competitividade e a acumulação que, como consequência, geram crises. Portanto, como já ressaltado anteriormente, "a crise capitalista não é temporária: é estrutural. Para que o capitalismo possa existir, a maioria precisa viver em condições desumanas" (Guzzo \& Lacerda Júnior, 2007, p.233). Tal fato consiste em um desafio para a Psicologia, contribuindo para que esta se individualize ou patologize os sujeitos, sendo a falta de uma leitura conjuntural um problema central da atuação do psicólogo em contextos de pobreza. É necessário que seja parte da formação e trabalho do profissional psi a análise histórica, junto com ações voltadas ao fortalecimento e organização dos sujeitos com os quais se trabalha, evitando politicismos, subjetivismos acerca da realidade, mas, também, de si próprio.

Nesse sentido, é importante ao psicólogo conceber sua atuação como política e a si como classe trabalhadora. Apesar de não ser o "sujeito revolucionário" - em decorrência dos elementos supracitados - o psicólogo pode contribuir para o desvelamento de algumas das contradições do sistema a estes sujeitos e ao seu fortalecimento, aliando seu trabalho técnico-político a uma militância anticapitalista (Oliveira \& Amorim, 2012; Martín-Baró, 2017).

É inquestionável, assim, a ideia de que há uma relação dialética entre desigualdade e subjetividade. Entretanto, hegemonicamente, entendeu-se a subjetividade como o que impossibilita a transformação, sendo patologizada e controlada. Por outro lado, o medo da simplificação ao indivíduo, sobretudo com o desenvolvimento da Psicologia Social crítica, fez com que alguns recaíssem num estruturalismo ou economicismo também errôneos. Há, assim,

"uma cilada mortífera à sua práxis: se o sujeito é um objeto que não pode se defender das determinações sociais, não há lugar para a ideia de transformação da sociedade; ou, uma vez que a subjetividade é efeito mecânico da presença do capitalismo e a individuação é exclusivamente a subjetivação de processos sóciohistóricos de submissão, resta-nos apenas conhecer e criticar os mecanismos de adestramento" (Sawaia, 2009, p. 365).

Finalizando, gostaríamos de indagar: A pobreza deve ser um tema ou fenômeno atrelado essencialmente à Psicologia Social ou à Psicologia Escolar e Educacional (quando aborda crianças e adolescentes)? Sendo a pobreza constitutiva da sociedade capitalista e atravessando parte dos sujeitos que nela se produzem e a produzem - ainda mais na realidade brasileira - não deveria ela atravessar todas as especialidades, áreas e subáreas do saber-fazer da Psicologia? Afinal, 
partimos do pressuposto que a Psicologia brasileira toma o ser humano e a realidade como objetos de estudo e intervenção, sobretudo, o brasileiro e a brasileira. Logo, não se trata de uma tomada de consciência individual, mas sim coletiva que vise primeiramente as condições objetivas comunitárias (Oliveira \& Guzzo, 2014). Dessa forma, as novas inserções dos profissionais psi exigem novos pressupostos e paradigmas, sobretudo no trabalho com a pobreza:

As perguntas críticas que os psicólogos devem se formular a respeito do caráter de sua atividade e, portanto, a respeito do papel que está desempenhando na sociedade, não devem centrar- se tanto no onde, nas no a partir de quem; não tanto em como se está realizando algo, quanto em benefício de quem; e, assim, não tanto sobre o tipo de atividade que se pratica (clínica, escolar, industrial, comunitária ou outra), mas sobre quais são as consequências históricas concretas que essa atividade está produzindo (Martin-Baró, 1996, p. 22).

\section{Considerações finais}

No intuito de entender como a Psicologia brasileira se apropria da pobreza e trabalha com ela, constatamos uma série de fluxos e refluxos, contradições inerentes ao campo do saber-fazer psi e à nossa sociedade, particularizada na realidade brasileira. Ao mesmo tempo em que há um movimento de autocrítica acerca do distanciamento com a realidade brasileira e de nossas insuficiências teórico-práticas, impulsionado por esta mesma realidade e suas necessidades, a hegemonia na Psicologia ainda se faz valer por meio de leituras e práticas individualizantes, psicologizantes, conformadas com a manutenção da ordem; ou que se aproximam da pobreza e da população pobre apenas fisicamente, como é o caso de atuações no âmbito das políticas públicas ou "na" comunidade. Apontamos para a necessidade de compreensão da pobreza como uma das expressões da questão social, mirando nas forças motrizes de nossa sociedade, de modo a visualizarmos, inclusive, os limites e potencialidades da profissão frente à totalidade, num sentido de contribuir para condições mais equânimes de vida.

Por fim, nos inspiramos em Martín-Baró (2006), quando este diz: "una Psicología de la liberación requiere una liberación previa de la Psicología, y esa liberación sólo llega de la mano con una praxis comprometida con los sufrimientos y esperanzas de los pueblos latinoamericanos" (p. 14). Logo, uma Psicologia que se diz compromissada com a compreensão e superação da pobreza, assim como do sistema que a forja e nela se sustenta, requer que 
identifiquemos e nos libertemos de nossa própria pobreza ontológica, epistemológica, metodológico-prática e ético-política.

\section{Referências}

Accorsi, A., \& Scarparo, H. (2016). Representações sociais da pobreza. In V. Ximenes, B. Nepomuceno, E. Cidade, \& J. Moura Jr. (Orgs.), Implicações Psicossociais da pobreza: diversidades e resistências. Fortaleza: Expressão Gráfica e Editora.

Accorssi, A., Scarparo, H., \& Guareschi, P. (2012). A naturalização da pobreza: reflexões sobre a formação do pensamento social. Psicologia \& Sociedade, 24(3), 536-546.

Azzi, E. (2010) A situação atual da profissão de psicólogo no Brasil. In O. H. Yamamoto \& A. L. Costa (Orgs.), Escritos sobre a profissão de psicólogo no Brasil (pp. 103-118). Natal: EDUFRN.

Botomé, S. P. (2010). A quem nós, psicólogos, servimos de fato?. In O. H. Yamamoto \& A. L. Costa (Orgs.), Escritos sobre a profissão de psicólogo no Brasil (pp. 169-202). Natal: EDUFRN.

Brasil. Presidência da República. (1962). Lei 4.119, de 27 de agosto de 1962. Dispõe sobre os cursos de formação em psicologia e regulamenta a profissão do psicólogo. Brasília: Presidência da República.

Cidade, E., Moura Jr., J., \& Ximenes, V. (2012). Implicações psicológicas da pobreza na vida do povo latino-americano. Psicologia Argumento, 30(68), 87-98.

Comim, F. V., Porto Jr., S., Moura Jr., J., \& Bagolin, I. (2016). Sem pobreza, mas com "fomes": visões econômicas e fisiológicas. In V. Ximenes, B. Nepomuceno, E. Cidade, \& J. Moura Jr. (Orgs.), Implicações Psicossociais da pobreza - diversidades e resistências (pp. 17-44). Fortaleza: Expressão Gráfica e Editora.

Conselho Federal de Psicologia (1988). Quem é o psicólogo brasileiro? São Paulo: EDICON.

Dantas, C. M. B., \& Yamamoto, O. H. (2010). Psicologia e pobreza no Brasil: produção de conhecimento e atuação do psicólogo. Psicologia \& Sociedade, 22(1), 104-111.

Euzébios Filho, A., \& Guzzo, R. S. L. (2009). Desigualdade social e pobreza: contexto de vida e de sobrevivência. Psicologia \& Sociedade, 21(1), 35-44.

Fontes, V. (2010). O Brasil e o capital-imperialismo: teoria e história ( 2 a ed.). Rio de Janeiro: EPSJV/Editora UFRJ .

Guzzo, R., \& Lacerda Júnior, F. (2007). Fortalecimento em tempo de sofrimento: reflexões sobre o trabalho do psicólogo e a realidade brasileira. Revista Interamericana de Psicología / Interamerican Journal of Psychology, 41(2), 231-240. 
Lacerda Júnior, F. (2010). Psicologia para fazer a crítica? Apologética, individualismo e marxismo em alguns projetos psi (Tese de Doutorado). Pontifícia Universidade Católica de Campinas, Programa de Pós-Graduação em Psicologia, Campinas, SP.

Lacerda Júnior, F. (2013). Capitalismo dependente e a psicologia no Brasil: das alternativas à psicologia crítica. Teoría y crítica de La psicología, 3, 216-263.

Lima, V. C. (2014). Psicologia da pobreza e pobreza da Psicologia: Um estudo sobre o trabalho do psicólogas(os) na política pública de assistência social (Dissertação de Mestrado). Pontifícia Universidade Católica de São Paulo, Programa de Estudos Pós-Graduados em Psicologia Social, São Paulo.

Macedo, J. P., Sousa, A. P., Carvalho, D. M., Magalhães, M. A., Sousa, F. M. S., \& Dimenstein, M. (2011). O psicólogo brasileiro no SUAS: quantos somos e onde estamos?. Psicologia em Estudo, 16(3), 479-489.

Martin-Baró, I. (1996). O papel do psicólogo. Estudos de Psicologia, 2(1), 7-27.

Martín-Baró, I. (2006). Hacia una Psicologia da Liberación. Revista Electrónica de Intervención Psicosocial y Psicología Comunitaria, 1(2), 7-14.

Martin-Baró, I. (2017). O latino indolente: caráter ideológico do fatalismo latino-americano. In I. Martin Baró, Crítica e Libertação na Psicologia (pp. 173-203). Petrópolis: Vozes.

Martins, J. (2003). Sociedade vista do abismo: novos estudos sobre exclusão, pobreza e classes sociais. Petrópolis: Editora Vozes.

Massimi, M. (2004). I deias psicológicas na cultura luso-brasileira, do século XVI ao século XVIII. In A. M. Jacó-Vilela, A. A. L. Ferreira, \& F. T. Portugal (Orgs.), História da Psicologia: rumos e percursos (pp. 75-84). Rio de Janeiro: Nau Editora.

Melsert, A. L. M., \& Bock, A. M. B. (2015). Dimensão subjetiva da desigualdade social: estudo de projetos de futuro de jovens ricos e pobres. Educação e Pesquisa, 41(3), 773-789.

Montaño, C. (2012). Pobreza, "questão social" e seu enfrentamento. Serviço Social \& Sociedade, (110), 270-287.

Moura Júnior, J. F., \& Ximenes, V. M. (2016). A identidade social estigmatizada de pobre: uma constituição opressora. Fractal: Revista de Psicologia, 28(1), 76-83.

Netto, J. P. (2011). Capitalismo Monopolista e Serviço Social (8a ed.). São Paulo: Cortez Editora.

Oliveira, I. F., \& Amorim, K. M. O. (2012). Psicologia e política social: o trato da pobreza como "sujeito psicológico". Psicologia Argumento, 30(70), 559-566.

Oliveira, L., \& Guzzo, R. (2014). Vida e obra de Martín-Baró e o paradigma da libertação. Revista Latino Americana de Psicologia Social I gnácio Martín Baró, 3(1), 205-230. 
Pereira, S. L. M. (2010). Psicologia: características da profissão. In O. H. Yamamoto, \& A. L. Costa (Orgs.), Escritos sobre a profissão de psicólogo no Brasil (pp. 141-162). Natal: EDUFRN.

Pessotti, I. (1988). Notas para uma história da Psicologia no Brasil. In Conselho Federal de Psicologia (Org.), Quem é o psicólogo brasileiro? (pp. 17-31). São Paulo: EDICON.

Sawaia, B. (2009). Psicologia e Desigualdade Social: uma reflexão sobre liberdade e transformação social. Psicologia \& Sociedade, 21(3), 364-372.

Silva, R. (2018). Psicologia e políticas públicas de enfrentamento de pobreza: Desafios para a formação e atuação de psicólogos(as) (Tese de Doutorado). Universidade de São Paulo, Instituto de Psicologia, São Paulo.

Yamamoto, O. H. (2009). Questão social e políticas públicas: Revendo o compromisso da psicologia. In A. M. B. Bock (Org.), Psicologia e compromisso social (pp. 37-54). São Paulo: Cortez.

Yamamoto, O. H., \& Oliveira, I. F. (2010). Política Social e Psicologia: uma trajetória de 25 anos. Psicologia: Teoria e Pesquisa, 26(spe), 9-24.

Ximenes, V. M., Moura Júnior, J., \& Lima, S. C. (2015). Pobreza e suas relações com a Psicologia Comunitária na 5 a Conferência Internacional de Psicologia Comunitária. Psicología, Conocimiento y Sociedad, 5(2), 156-181.

\author{
Endereço para correspondência \\ Kíssila Teixeira Mendes \\ Universidade Federal de Juiz de Fora - UFJF \\ Programa de Pós-Graduação em Psicologia \\ Campus Universitário, Rua J osé Lourenço Kelmer, s/n - São Pedro, CEP 36036-900, \\ Juiz de Fora - MG, Brasil \\ Endereço eletrônico: kissilamm@hotmail.com
}

Pedro Henrique Antunes da Costa

Universidade Federal da Paraíba - UFPB

Programa de Pós-Graduação em Psicologia Social

CCHLA, Cidade Universitária, CEP 58051-900, J oão Pessoa - PB, Brasil

Endereço eletrônico: phantunes.costa@gmail.com

Recebido em: 11/11/2018

Aceito em: 03/12/2018

\title{
Notas
}

* Psicóloga e Cientista Social; Mestre e Doutoranda em Psicologia na Universidade Federal de Juiz de Fora.

** Psicólogo, Mestre e Doutor em Psicologia na Universidade Federal de Juiz de Fora.

Este artigo de revista Estudos e Pesquisas em Psicologia é licenciado sob uma Licença Creative Commons Atribuição-Não Comercial 3.0 Não Adaptada. 